\title{
Süperkritik Brayton Çevriminin Termodinamik Analizi
}

\author{
Volkan CEYLAN (D) $1^{*}$, Arif Emre ÖZGÜR (iD2 \\ ${ }^{1}$ Avrasya Üniversitesi, Meslek Yüksekokulu, 61040 Trabzon \\ ${ }^{2}$ Isparta Uygulamalı Bilimler Üniversitesi, Teknoloji Fakültesi, Makine Mühendisliği Bölümü, 32260 Isparta \\ Geliş Tarihi (Received): 11.10.2021, Kabul Tarihi (Accepted): 12.12.2021 \\ $\square$ Sorumlu Yazar (Corresponding author*): emreozgur@isparta.edu.tr \\ (c) +902462146773 등 +902462146899
}

\section{ÖZ}

Gaz türbini çevrimlerinde, son on yılda yapılan çalışmalarda önemli gelişmeler görülmektedir. Bununla birlikte çevrimin verimini attırabilmek için farklı uygulamalar üzerine çalışmalar yapılmaktadır. Bu çalışmada, ayrı ayrı $\mathrm{CO}_{2}(k a r-$ bondioksit veya R744) ve hava akışkanlı süperkritik Brayton çevrimlerinin termodinamik analizi yapılmıştır. Süperkritik koşullarda çalışan çevrim ekipmanlarının farklı çevrim parametrelerinde enerji ekserji verimliliği ve net gücü alınarak, türbin giriş sıcaklık ve basıncının etkileri, kompresör basınç oranı ve kompresör verimlerinin performans üzerine etkileri incelenmiştir. Analiz çalışması bir bilgisayar yazılımı (Engineering Equation Solver-EES) ile çözümlenmiştir. Güç çevrimlerindeki verim artışına, süperkritik $\mathrm{CO}_{2}\left(\mathrm{~S}-\mathrm{CO}_{2}\right)$ türbinlerinin etkisi değerlendirilmiş ve enerji sektöründeki geleceği tartışılmıştır.

Keywords: Brayton çevrimi, süperkritik karbondioksit $\left(\mathrm{S}-\mathrm{CO}_{2}\right)$, termodinamik analiz, türbin

\section{Thermodynamic Analysis of a Supercritical Brayton Cycle}

\begin{abstract}
Enormous strides have been made on gas turbine cycles in recent years. In addition, different practices of studies are being carried on in order to increase the cycle efficiency. In this study, $\mathrm{CO}_{2}$ (carbon dioxide or R744) and thermo dynamic analysis of supercritical Brayton cycles having air flow fluidity have separately been studied. Cyclical equipment working in supercritical conditions and its energy exergy performance at different cycles of parameters, and turbine inlet temperature and the effects of pressure, and compressor pressure ratio, and compressor efficiency on performance are surveyed examined. Analyze work is sorted out through a computer software (Engineering Equation Solver-EES).Supercritical $\mathrm{CO}_{2}\left(\mathrm{~S}-\mathrm{CO}_{2}\right)$ turbine effects on efficiency increase in power conversions are evaluated and its future in the energy sector is discussed.
\end{abstract}

Keywords: Brayton cycle, supercritical carbondioxide $\left(\mathrm{S}-\mathrm{CO}_{2}\right)$, thermodynamic analysis, turbine

\section{GíRiş}

Gaz türbinli sistemler Brayton çevrimi olarak adlandırılmakta olup bu çevrim ile mekanik güç üretimi yapılmaktadır. Brayton çevrimi ilk olarak 19. yüzyılın son çeyreklerinde George Brayton tarafından tasarlanmıştır. 20. yüzyılın ilk yarılarına kadar fazla gelişim göste- rememiş, düşük izentropik verimler ve türbin giriş sıcaklıklarından dolayı düşük ısıl verim elde edilmiştir (Çetin, 2017). Bu yüzyılın ikinci yarısından sonra büyük teknolojik gelişmeler gözlenmiştir. Özellikle son yıllarda, gaz türbinli çevrimlerde farklı akışkanlar kullanılarak, sistemdeki verimin arttırılabileceği değerlendirilmiş ve uygulamalar yapılmıştır. Sistemde kullanılacak 
akışkana göre gaz türbinleri, açık çevrim (aracı akışkan olarak hava), kapalı çevrim (aracı akışkan olarak hava veya farklı bir akışkan), ve yarı açık çevrim olmak üzere sınıflandırılabilmektedir (Tozlu ark., 2017).

Gaz türbinlerinin tercih edilme sebepleri, kurulumu basit ve hafif olmaları, az yer kaplamaları, kurulum maliyetinin düşük olması, diğer çevrimlere göre çok hızlı devreye girip çıkabilmeleri ve güvenilirliklerinin yüksek olmasıdır. Bununla birlikte yolcu, donanma ve yük gemilerinde, hava araçlarında, elektrik güç santrallerinde tercih edilmektedir. Gaz türbinlerinde ısıl kaynak olarak güneş enerjisi, jeotermal enerji, fosil yakıt, nükleer ve biyokütle kullanılırken, akışkan olarak hava, azot, helyum, karbondioksit gibi akışkanlar kullanılabilmektedir. Günümüzde süperkritik buharlı güç santrallerinde akışkanın (su buharı) türbine giriş sıcaklığı $620^{\circ} \mathrm{C}$ değerlerine kadar yükseltilmiştir (Korpela, 2011). Gaz türbinlerinde ise bu sınır $1425^{\circ} \mathrm{C}$ seviyelerine çıkabilmektedir (Horlock, 1997; Çengel, 2008). Süperkritik Brayton çevrimlerinde türbinlerde kullanılan çelik alaşımlarının dayanım sınırı, türbine girmekte olan akışkan sıcaklığını etkilemektedir. Daha yüksek sıcaklık ve basınçta türbine giren akışkan, türbin kanatçıklarını deformasyona uğratabilmektedir. Bunun önüne geçebilmek için ise nikel ya da seramik kaplamalı alaşımlar kullanılmaktadır. Mevcut ebatlardaki kanatçıkların nikel vb. alaşımlar ile üretilmesi ilk yatırım maliyetini arttırmaktadır. Maliyetlerin en az seviyeye indirilebilmesi için daha küçük ebatlarda türbin üretilmesi gerekmektedir (Özgür ve Ceylan, 2019). Bu amaç doğrultusunda, çevrim akışkanı olarak karbondioksit $\left(\mathrm{CO}_{2}\right)$ kullanımı etkili bir yöntem olarak gündeme gelmiştir (Angela, 1968; Coms, 1997).

$\mathrm{CO}_{2}$ çevre problemlerinin (sera etkisi ve küresel ısınma) etkisini arttırmasıyla, önemli bir akışkan durumuna gelmiştir. $\mathrm{CO}_{2}$ 'in kritik nokta sıcaklığı düşüktür. $\left(30,98^{\circ} \mathrm{C}\right)$ Aynı zamanda ozon delme potansiyeli (ODP) sıfırdır ve küresel ısınma potansiyeli (GWP-100 yıllık) 1 olarak tanımlanmış bir akışkandır (Özgür, 2014). Göreceli olarak düşük viskozitesi, yüksek hacimsel buharlaşma gizli ısısı, düşük maliyet, yüksek ısıl iletkenlik ve yüksek buhar yoğunluğuna sahip olması, karbondioksitin $\left(\mathrm{CO}_{2}\right)$ tercih edilme nedenlerindendir (Kim ark., 2004). Dostal ve ark. (2004) ile Kato ve ark. (2004), S- $\mathrm{CO}_{2}$ (Süperkritik-CO 2 ) Brayton güç çevrimleri ile ilgili çalışmalar yapmışlar ve yaptıkları bu çalışmalar büyük ilgi görmüştür. Son on yılda, $\mathrm{S}-\mathrm{CO}_{2}$ Brayton çevrimleri ile ilgili nükleer ve yenilenebilir enerji temelli enerji üretimi başta olmak üzere birçok alanda uygulamalı olarak çalışmalar yapıldığı görülmektedir. Wright ark. (2010) Sandia Ulusal Laboratuarları'nda güneş, nükleer veya fosil ısı kaynaklarıyla elde edilen, kritik üstü sıcaklıktaki çeşitli çevrim akışkanlarını kullanarak, Brayton çevrimlerinin performansını araştırmaktadır. Hedeflenen sıcaklık aralığında, $\mathrm{S}-\mathrm{CO}_{2}$ çevriminin, yüksek verimlilik potansiyeli ve daha düşük sermaye maliyetleri ile ön plana çıktığı görülmektedir. Muto ark. (2016) güneş enerjisi ile çalıştırılan, $\mathrm{CO}_{2}$ akışkanlı Rankine ve Brayton çevrimlerinin ısıl verimliliğini karşılaştırmıştır. Rankine çevriminde $\mathrm{CO}_{2}$ basıncı $20 \mathrm{MPa}$ basınç, Brayton çevriminde ise $8 \mathrm{MPa}$ olarak kabul edilmiştir. İki sistemde de türbin giriş sıcaklığı $650^{\circ} \mathrm{C}$ olarak alınmış ve aralarında $\% 2,5$ verim farkı olduğunu tespit edilmiştir. Padilla ark. (2016) ısıl kaynak olarak güneş enerjisinden faydalanarak, sekiz farklı S- $\mathrm{CO}_{2}$ konfigürasyonu için enerji ve ekserji analizi sunmuştur. Ara soğutmalı, kademeli sıkıştırmalı Brayton çevriminin en iyi ısıl ve ekserjetik performansa sahip olduğunu ifade etmişlerdir. Ahn ark. (2015) nükleer reaktörlerde uygulamak için $\mathrm{S}-\mathrm{CO}_{2}$ Brayton çevriminin çeşitli konfigürasyonlarını araştırmıştır. $450^{\circ} \mathrm{C}$ ile $600^{\circ} \mathrm{C}$ türbin giriş sıcaklığı aralığında, reküperatörlü Brayton çevriminin nispeten daha verimli çalışabileceğini belirtmiştir. Holcomb ark. (2016) $\mathrm{S}-\mathrm{H}_{2} \mathrm{O}$ ve $\mathrm{S}-\mathrm{CO}_{2}$ akışkanları için nikel bazlı alaşım türbin rotor kanatlarının oksidasyon davranışlarını karşılaştırmıştır. Deneylerde $\mathrm{S}-\mathrm{CO}_{2}$ çevrimi için $730^{\circ} \mathrm{C}$ ve 207 bar, S- $\mathrm{H}_{2} \mathrm{O}$ çevrimi için $726^{\circ} \mathrm{C}$ ve 208 bar değerlerini test etmişlerdir. S- $\mathrm{CO}_{2}$ çevriminde kayda değer bir korozyon görülmediğini, $\mathrm{S}-\mathrm{H}_{2} \mathrm{O}$ durumunda ise korozyon hızında artış olduğunu tespit etmişlerdir.

\section{MATERYAL VE YÖNTEM}

Bu çalışmada S- $\mathrm{CO}_{2}$ Brayton çevriminin ve hava Brayton çevriminin termodinamik analizi yapılmış ve bazı çevrim parametrelerinin (türbin giriş sıcaklığı, türbin giriş basıncı, kompresör giriş sıcaklığı kompresör basınç oranı, kompresör ve türbin verimleri) çevrimin enerji ve ekserji verimliliğine etkisi incelenmiştir. Literatürdeki çalışmalardan farklı olarak, çevrimdeki iş akışkanın $\mathrm{CO}_{2}$ ve hava olması durumları için analiz sonuçları kıyaslanmıştır. Bununla birlikte, türbin giriş yoğunlukları baz alınarak, sabit eksenel hız durumunda oluşan, türbin giriş kesitleri, $\mathrm{CO}_{2}$ için karşılaştırılmıştır. Çevrimin parametrik analizi ve akışkanlara ait termofiziksel özellikler EES (Engineering Equation Solver) yazılımı ile gerçekleştirilmiştir (Klein, 2020).

Brayton çevriminde çevrim akışkanının basıncı ve sıcaklığı, kompresör tarafından yükseltilir. Daha sonra herhangi bir ısı kaynağı ile akışkanın sıcaklığı, türbin giriş değerine yükseltilir. Türbin kanatçıkları üzerinden akışkanın geçirilmesi ile mekanik iş elde edilir. Türbin çıkışında, akışkanın basıncı, sıcaklığına oranla daha büyük oranda düşer. Türbin çıkışındaki ısı eşanjörü va- 
sıtasıyla, belirli miktar ısı başka bir ortama aktarııı. Sıcaklığı azalan akışkan, tekrar kompresör tarafından basınçlandırılır. Brayton çevriminin sistem şeması Şekil 1'de verilmiştir.

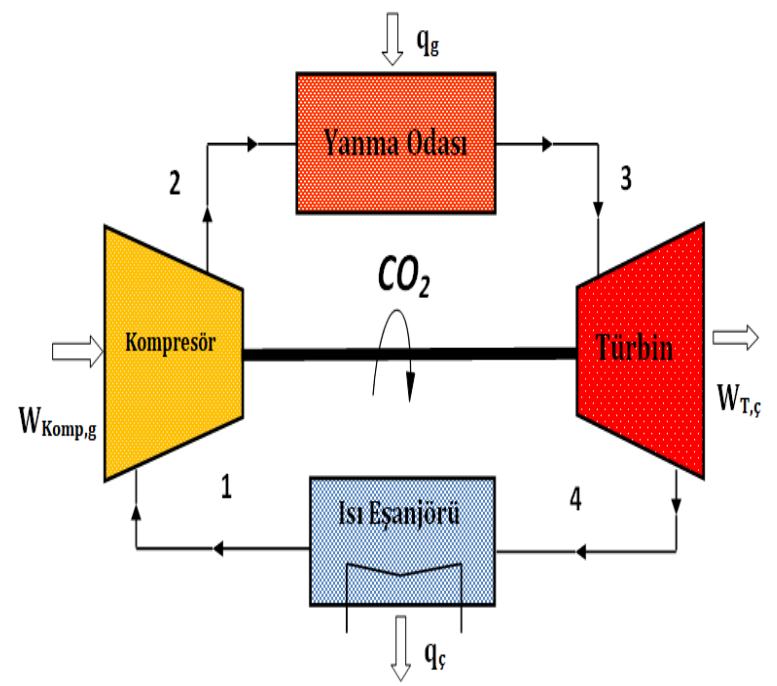

Şekil 1. Brayton çevrimi sistem şeması

Çevrimin analizinde yapılan bazı kabuller aşağıda belirtilmiştir;

- Çevrim bileşenlerinden olan ısıl kayıplar ve bileşenler içindeki akışkana ait basınç kayıpları inmal edilmiştir.

- Sistemin sürekli rejim şartlarında olduğu kabul edilmiştir.

- Kinetik enerji ve potansiyel enerji değişimleri ihmal edilmiştir.

- Kompresör giriş sıcaklığı $25^{\circ} \mathrm{C}$ olarak alınmıştır. Çevrimdeki performansını değerlendirmek için $20^{\circ} \mathrm{C}$ ile $50^{\circ} \mathrm{C}$ arasındaki değerler alınmıştır.

- Çevrim minimum basıncı 8 MPa'dır.

- Çevrim basınç oranları 2 ile 4,25 arasındaki değerler alınarak türbin giriş basıncı $16 \mathrm{MPa}$ ile 34 MPa arasındaki değerlerde çalışılmıştır.

- Türbin giriş sıcaklıkları $600^{\circ} \mathrm{C}$ ile $1000^{\circ} \mathrm{C}$ arasında değişmektedir.

Türbin ve kompresör verimleri sırasıyla $\% 90$ ve $\% 89$ 'dur. Her iki çevrim elemanı için sistemdeki performansını değerlendirmek amacıyla \%70 ile \%90 arasındaki değerler alınmıştır. S- $\mathrm{CO}_{2}$ Brayton çevrimi ve hava Brayton çevriminin T-s diyagramları, öngörülen parametreler ile Şekil 2'de verilmiştir.
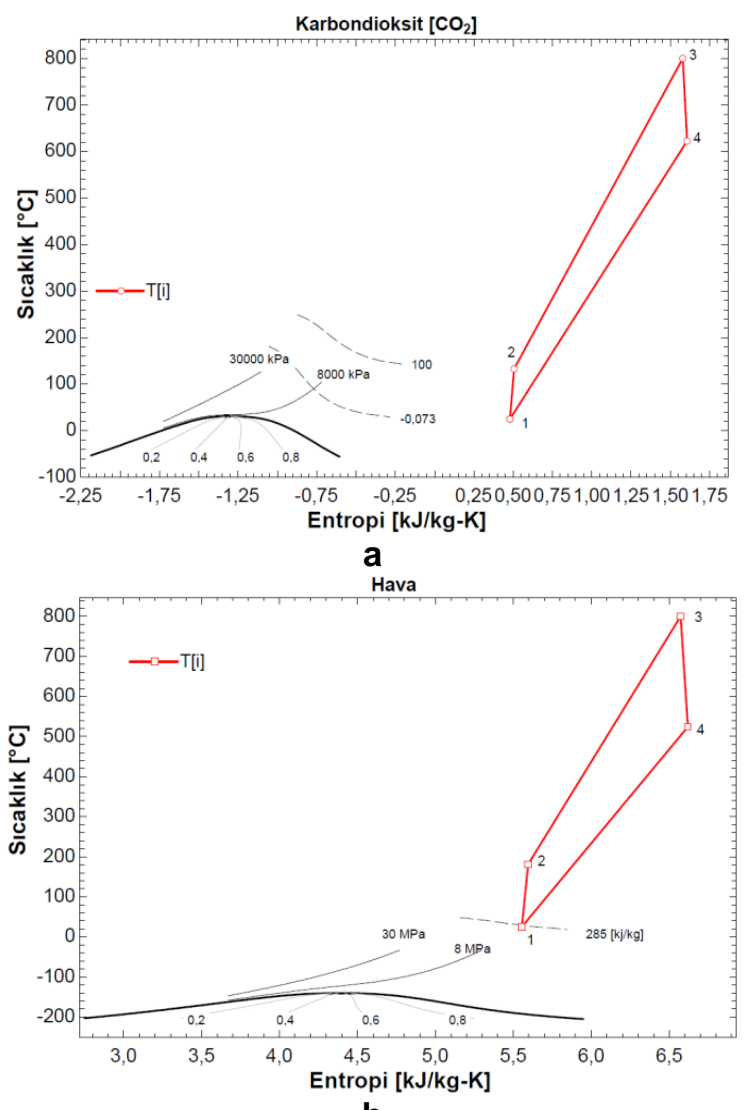

b

Şekil 2. a. $\mathrm{S}-\mathrm{CO}_{2}$, b. Hava Brayton çevrimleri T-s diyagramı

Çevrim bileşenlerinin enerji ve ekserji analizleri için kullanılan eşitlikler Eşitlik 1'den Eşitlik 12'ye kadar aşağıda verilmiştir.

Basınç Oranı;

$$
P_{r c}=\frac{\mathrm{P}_{2}}{\mathrm{P}_{1}}
$$

Kompresör;

$$
\begin{array}{r}
\dot{W}_{\text {kompresör }}=\dot{m}_{\mathrm{CO}_{2}} \cdot\left(h_{2}-h_{1}\right)=\dot{m}_{\mathrm{CO}_{2}}\left[c_{p C O_{2}\left(T_{2}\right)} T_{2}-\right. \\
\left.c_{p C O_{2}\left(T_{1}\right)} \cdot T_{1}\right] \\
\dot{m}_{\mathrm{CO}_{2}} \cdot \varepsilon_{1}+\dot{W}_{\text {kompresör }}=\dot{m}_{\mathrm{CO}_{2}} \cdot \varepsilon_{2}+I_{\text {kompresör }}
\end{array}
$$

Yanma Odası;

$$
\begin{gathered}
\dot{Q}_{\text {Yanmao. }}=\dot{m}_{\mathrm{CO}_{2}} \cdot\left(h_{3}-h_{2}\right)=c_{\mathrm{pCO}_{2}}\left(T_{3}-T_{2}\right) \\
I_{\text {Yanmao. }}=\dot{m}_{\mathrm{CO}_{2}} \cdot T_{0} \cdot\left[\left(s_{3}-s_{2}\right)+\frac{q_{Y a n m a O}}{T_{3}}\right]
\end{gathered}
$$


Türbin;

$$
\begin{gathered}
\dot{W}_{\text {türbin }}=\dot{m}_{\mathrm{CO}_{2}} \cdot\left(h_{3}-h_{4}\right)=\dot{m}_{\mathrm{CO}_{2}} \cdot\left(c_{p C O_{2} T_{3}} \cdot T_{3}-\right. \\
\left.c_{p C O_{2} T_{4}} \cdot T_{4}\right)
\end{gathered}
$$

Isı Eşanjörü;

$$
\begin{gathered}
\dot{Q}_{\text {eşanjör }}=\dot{m}_{\mathrm{CO}_{2}} \cdot\left(h_{4}-h_{1}\right)=c_{p C O_{2}}\left(T_{4}-T_{1}\right) \\
I_{\text {eşanjör } r}=\dot{m}_{C O_{2}} \cdot T_{0} \cdot\left[\left(s_{1}-s_{4}\right)+\frac{q_{\text {esanjör }}}{T_{0}}\right]
\end{gathered}
$$

Çevrimin enerji ve ekserji verimi;

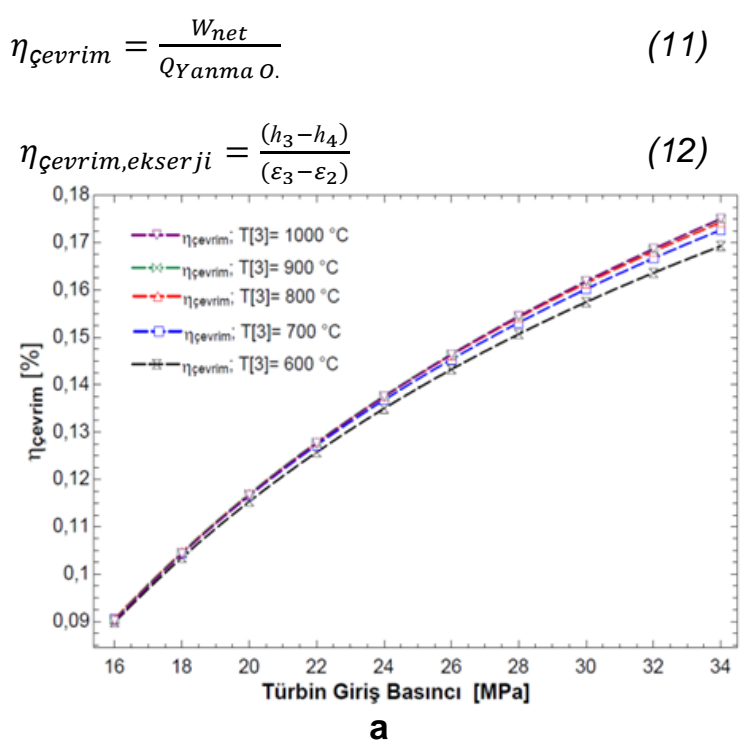

\section{BULGULAR VE TARTIŞMA}

Bu bölümde Eşitlik 1'den Eşitlik 12'ye kadar olan yöntem takip edilerek çeşitli parametrelerin değişiminin sistemdeki performansı üzerine etkisi incelenmiştir. S$\mathrm{CO}_{2}$ Brayton çevrimi ve hava Brayton çevrimi için yüksek türbin giriş basınç ve sıcaklıklarında çevrimin enerji verimi Şekil 3'de verilmiştir. Çevrimlerde türbin verimi \%90, kompresör verimi ise \%89'dir. Her iki çevrimde de türbin giriş sıcaklıkları ultrasüperkritik seviye olup türbin giriş basıncı arttıkça çevrim verimi artmaktadır. Şekil 3a da gösterilen S-CO 2 Brayton çevriminde sabit türbin giriş basıncında, türbin giriş sıcaklığı arttırıldığında çevrim enerji verimi için dikkate alınacak bir artış olmadığı görülmektedir. Ancak Şekil $3 b$ hava Brayton çevriminde ise $\mathrm{S}-\mathrm{CO}_{2}$ nin aksine maksimum türbin giriş basıncında $(P[3]=34 \mathrm{MPa})$ türbin giriş sıcaklıkları arasındaki $600^{\circ} \mathrm{C}$ ile $1000^{\circ} \mathrm{C}$ değerlerine bakıldığında çevrim enerji verimi \%2,42 arttığı görülmektedir

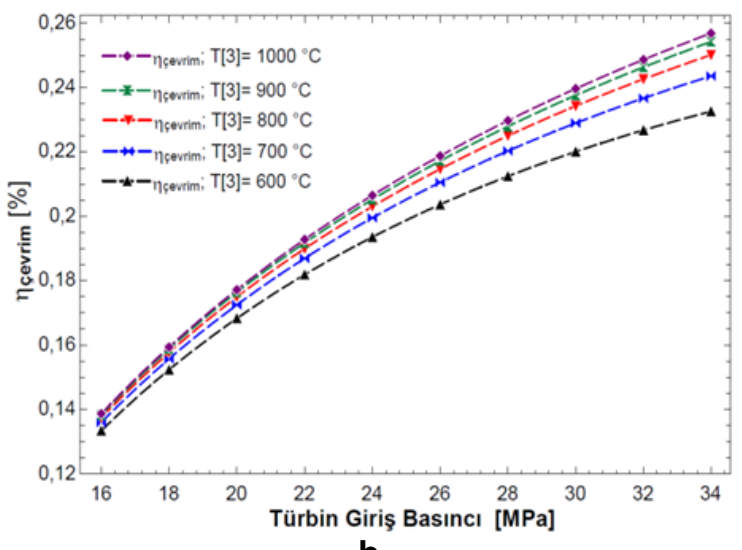

b

Şekil 3. a. S-CO $\mathrm{CO}_{2}$ b. Hava Brayton çevrimi türbin giriş basıncı ile çevrim enerji verimi değişimi

$\mathrm{S}-\mathrm{CO}_{2}$ Brayton çevrimi ve hava Brayton çevrimlerinde ekserji verimleri incelendiğinde türbin giriş basıncının arttırılması ekserji verimi yükseltmektedir. Ancak sabit basınçta türbin giriş sıcaklıklarının arttırılması ekserji verimini azaltmaktadır. Şekil 4a'da $\mathrm{S}-\mathrm{CO}_{2}$ ve Şekil 4b'de Hava Brayton çevrimlerinde türbin giriş basıncı ile çevrim ekserji verimi değişimi gösterilmiştir. Hava (b) Brayton çevriminde türbin giriş sıcaklığının $600^{\circ} \mathrm{C}$ olduğu değere incelendiğinde maksimum basınç olan $34 \mathrm{MPa}$ türbin giriş basıncında çevrim ekserji verimi \%115,9'a ulaşmaktadır. Bu değer çevrimdeki en yüksek ekserji verim değeridir. 

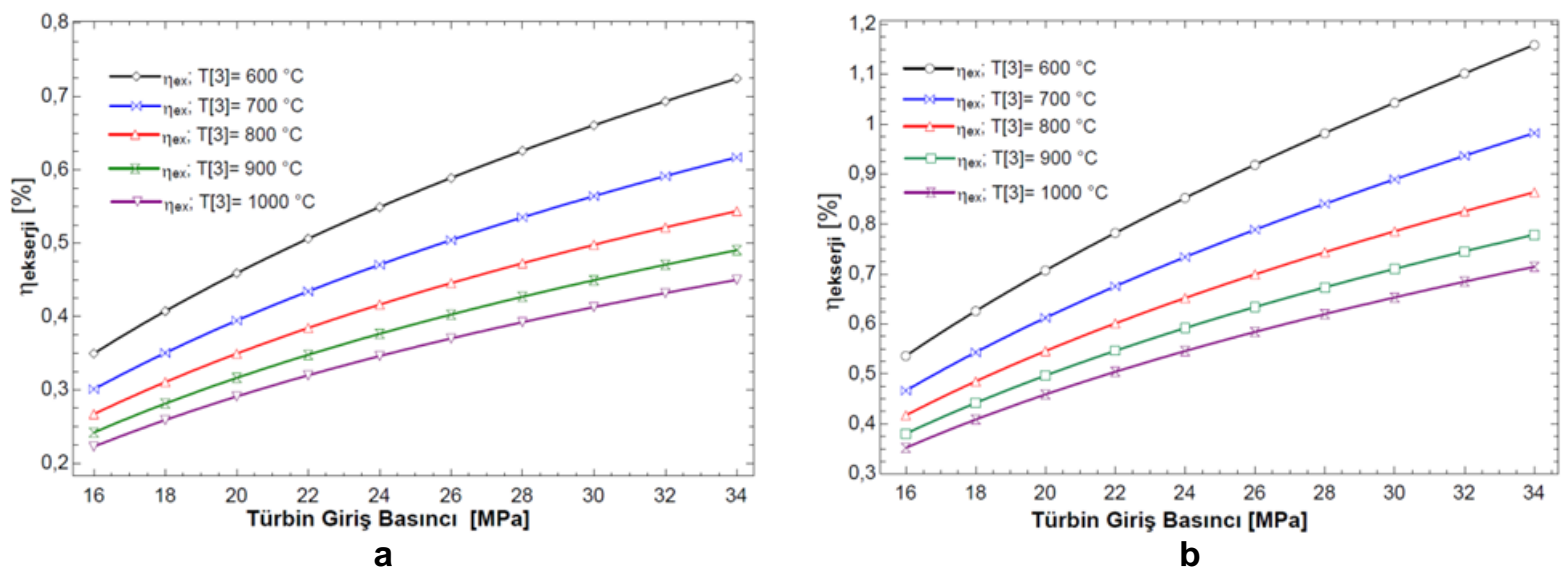

Şekil 4. a. S-CO $-\mathrm{CO}_{2}$ b. Hava Brayton çevrimi türbin giriş basıncı ile çevrim ekserji verimi değişimi
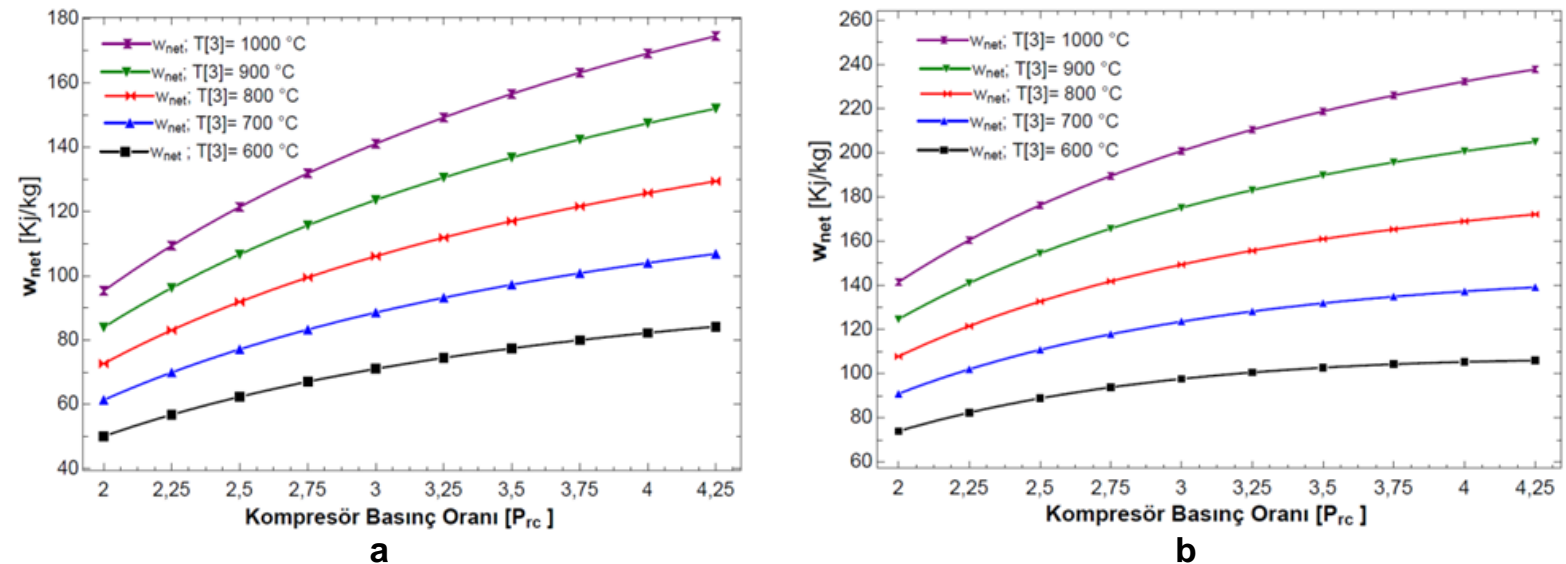

Şekil 5. a. S-CO 2 , b. Hava Brayton çevrimi kompresör basınç oranı ile çevrim net gücünün değişimi

Şekil 5a'da S- $\mathrm{CO}_{2}$ ve Şekil 5b'de Hava Brayton çevrimi kompresör basınç oranı ile çevrim net gücünün değişimi gösterilmektedir. Şekillerde de görüldüğü gibi kompresör basınç oranı veya türbin giriş basıncı arttırıldığında çevrim net gücü artmakta olup yüksek türbin giriş sıcaklıklarının seçilmesi daha yüksek çevrim gücünün elde edilmesinde etkilidir. Ancak Hava (b) Brayton çevriminde eğrilerdeki yatay seyirler göstermektedir ki türbin giriş basıncı arttırıldığında çevrim net gücü maksimuma ulaşmakta daha sonra düşmektedir. $1000^{\circ} \mathrm{C}$ ve üzerindeki türbin giriş sıcaklıklarında net gücün maksimuma ulaşıp düşmesi daha yüksek kompresör basınç oranlarında gerçekleşeceği anlaşılmaktadır. Bu durumda Hava (b) Brayton çevrimlerinde uygun parametrelerin belirlenmesi oldukça önemlidir.

Performans değerlerinin hesaplamasında Şekil 6 ve Şekil $7^{\prime}$ de sabit kompresör giriş sıcaklığı $\left(T[1]=25^{\circ} \mathrm{C}\right)$ ve basıncı $(P[1]=8 \mathrm{MPa})$ ile sabit türbin giriş basıncında $(P[3]=30 \mathrm{MPa})$ farklı kompresör verimleri için ultrasüperkritik türbin giriş sıcaklıklarındaki çevrimin enerji ve ekserji verimlerinin değişimleri gösterilmiştir. Türbin verimi \%90 olarak alınmıştır. Kompresör verimleri olarak \%70-90 arasındaki verim değerleri incelenmiştir. Her iki çevrimde de görüldüğü gibi $600^{\circ} \mathrm{C}^{\prime}$ lik türbin giriş sıcaklığında kompresör verimleri arttırıldıkça çevrim enerji verimi daha hızlı artmaktadır. Türbin giriş sıcaklıkları arttırılığında ise çevrim enerji veriminin artmasına etkisi ilk sıcaklıktaki gibi olmadığı görülmektedir. Şekil 7 incelendiğinde sıcaklık ve kompresör verimi arttıkça ekserji verimi azalmaktadır. Aynı değerlerde bu sefer kompresör verimi $\eta_{\text {kompresör }}=0,89$ (\%89) sabit tutularak türbin giriş sıcaklıklarının farklı kompresör giriş sıcaklıklarında çevrim enerji verimine etkisi Şekil 8'de gösterilmiştir. Kompresör giriş sıcaklıklarının artması çevrim enerji verimini düşürmektedir. Bu sebepten dolayı ultrasüperkritik sıcaklıkta çalışan Brayton çevrimlerinde türbin çıkış sıcaklıklarının yüksek olmasından dolayı yardımcı ekipmanlar kullanarak kompresör giriş sıcaklığını düşük tutmak oldukça önemlidir. 


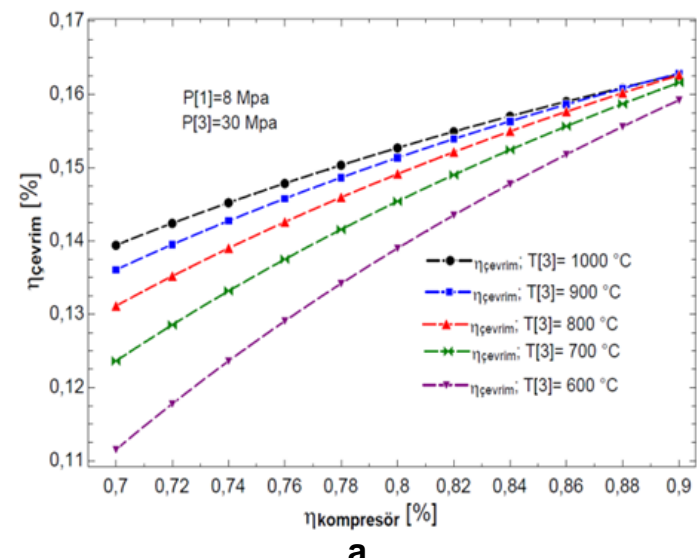

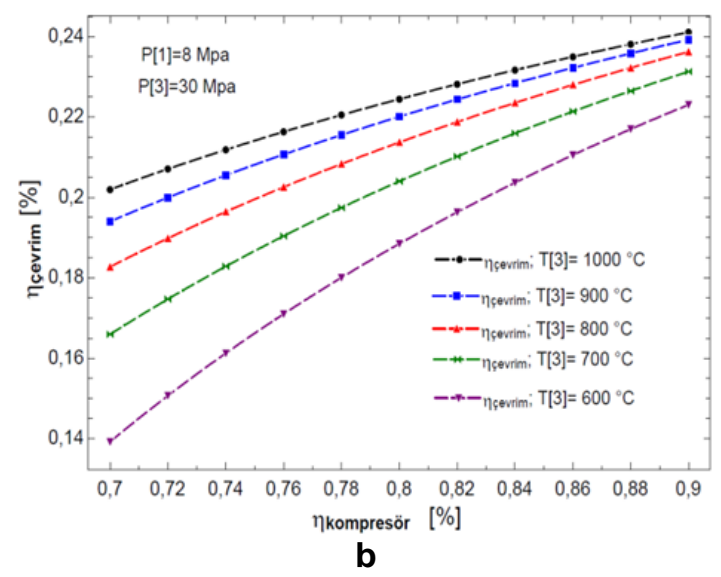

Şekil 6. a. S- $\mathrm{CO}_{2}$, b. Hava Brayton çevrimi kompresör verimi ile çevrim enerji verimi değişimi

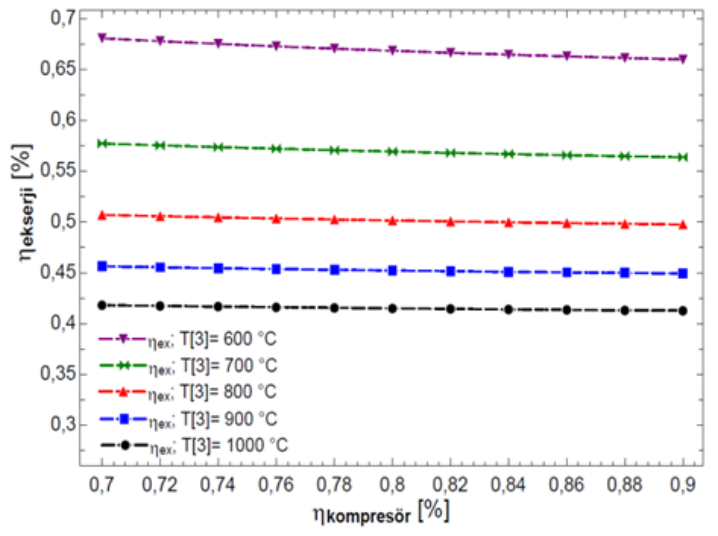

a

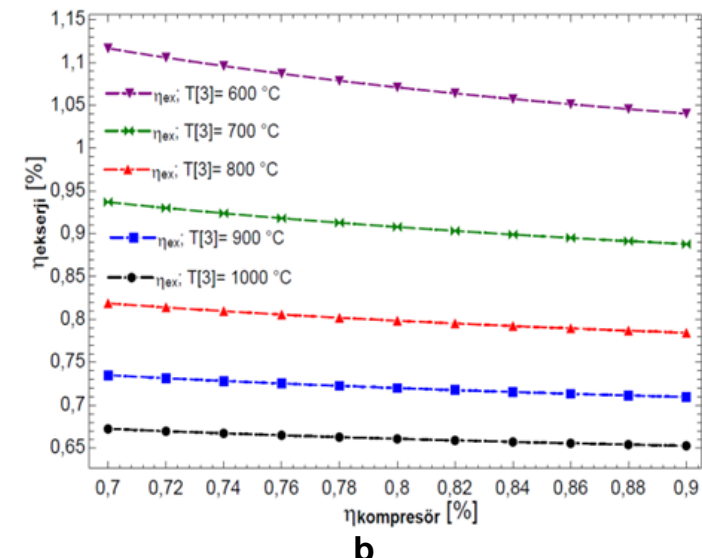

Şekil 7. a. S-CO $\mathrm{CO}_{2}$ b. Hava Brayton çevrimi kompresör verimi ile çevrim ekserji verimi değişimi

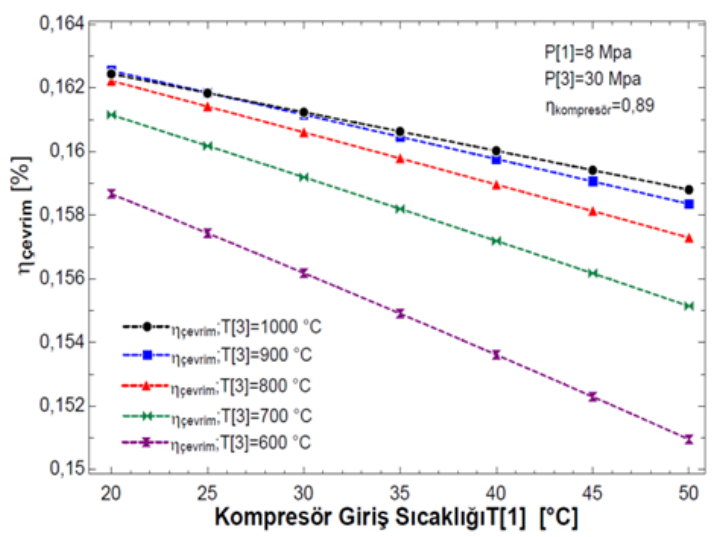

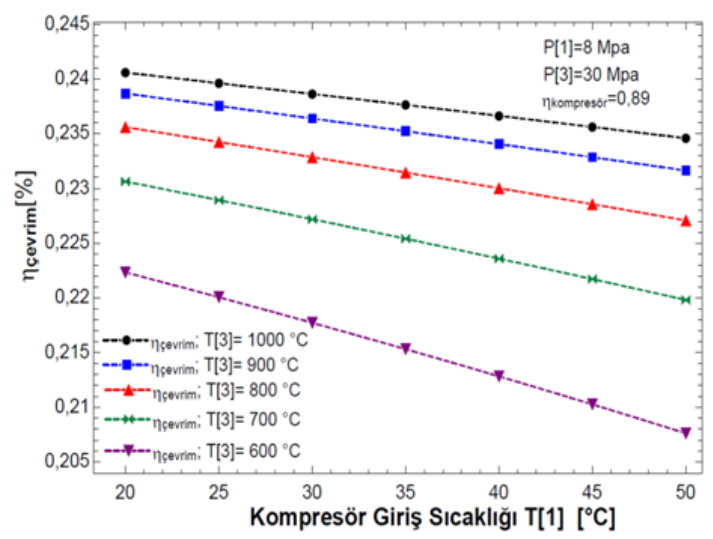

b

Şekil 8. a. S- $\mathrm{CO}_{2}$, b. Hava Brayton çevrimi kompresör giriş sıcaklıkları ile çevrim enerji verimi değişimi

Şekil 9 ve Şekil $10^{\prime} \mathrm{da} 700^{\circ} \mathrm{C}$ gibi sabit türbin giriş sıcaklığında \%70 ile \%89 arasındaki beş farklı kompresör verimlerinin çevrim enerji ve ekserji verimlerine etkisi incelenmiştir. Görülmektedir ki sabit türbin giriş sı- caklığında kompresör basınç oranı ve kompresör verimi arttırıldığında çevrim enerji ve ekserji verimi artmaktadır. Her iki çevrim içinde kompresör basınç oranı arttığında minimum değer ile maksimum değer sonucunda ekserji verimleri iki katına çıkmaktadır. Şekiller 
incelendiğinde sabit basınç değerinde sadece kompresör verimleri arttırıldığında çevrim enerji verimi artmasına karşılık ekserji verimlerindeki artış ise her iki çevrim içinde yok denecek kadar azdır. $\mathrm{S}-\mathrm{CO}_{2}$ (a) Brayton çevrimlerinde sabit türbin giriş sıcaklığında $\left(\mathrm{T}[3]=700^{\circ} \mathrm{C}\right.$ ) çevrimde en yüksek kompresör basınç oranı olarak hesaplanan $4,25(\mathrm{P}[3]=34 \mathrm{MPa})$ oranı ve

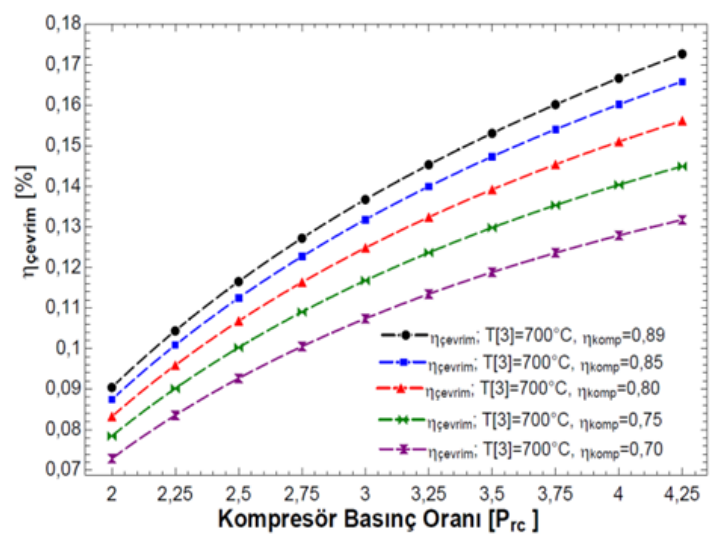

a kompresör verimleri en yüksek değer olan \%89 verimde alınmıştır. Çevrim enerji verimi ile en düşük kompresör verimi olan $\% 70$ verim arasında $\% 4,10$ gibi fark olmasına karşılık hava Brayton çevriminde bu fark $\% 7,27$ 'dir.

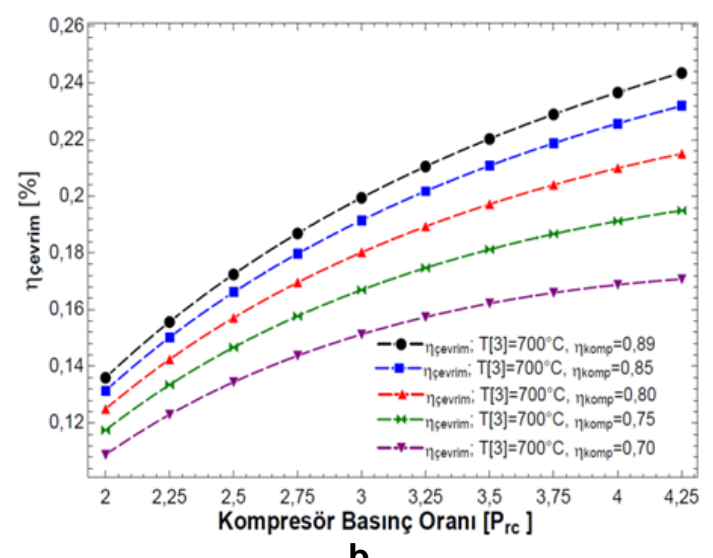

b

Şekil 9. a. S- $\mathrm{CO}_{2}$, b. Hava, farklı basınç oranlarında çevrim enerji verimine kompresör veriminin etkisi
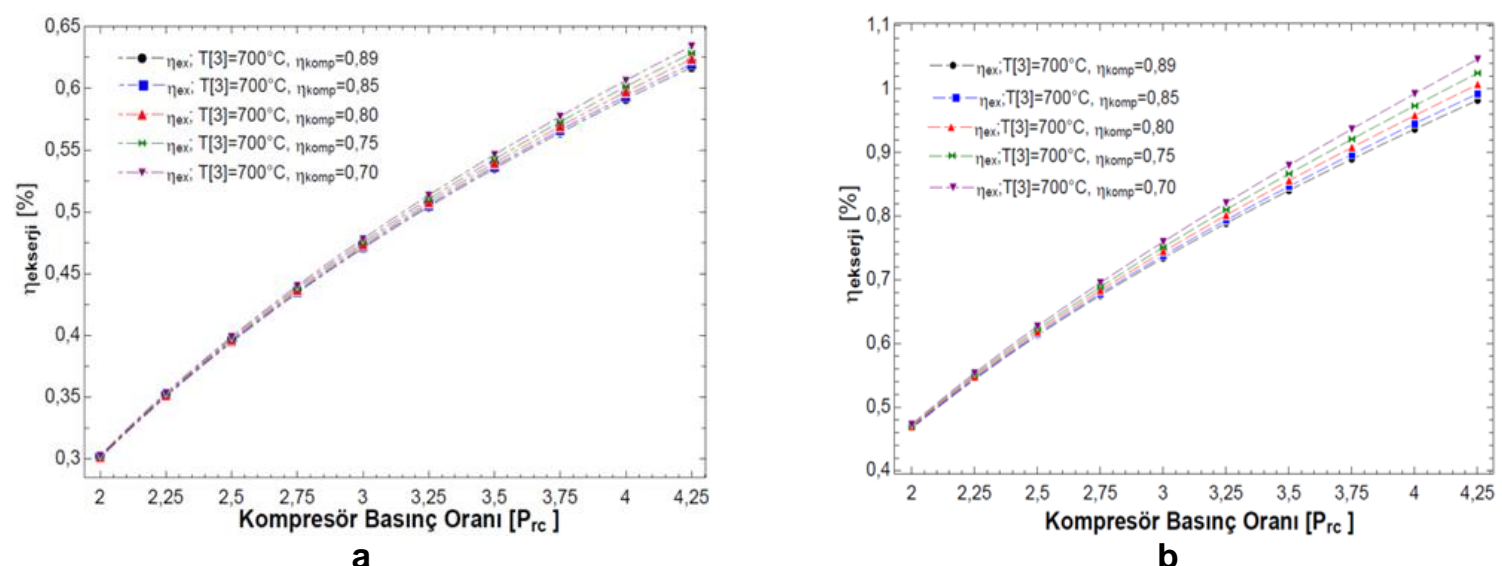

Şekil 10. a. S- $-\mathrm{CO}_{2}$, b. Hava, farklı basınç oranlarında çevrimin ekserji verimine komp. veriminin etkisi

Her iki çevrim için farklı kompresör basınç oranlarında kompresör verimlerinin çevrim net güce etkisi Şekil $11^{\prime}$ de sunulmuştur. Şekil incelendiğinde $700^{\circ} \mathrm{C}$ sabit türbin giriş sıcaklığında kompresör basınç oranları arttırıldığında çevrim net gücü artmaktadır. Hava (b) Brayton çevriminde görülmektedir ki \%70 gibi düşük kompresör veriminde çalışan çevrimde net güç 3,75 kompresör basınç oranında $90,38 \mathrm{kj} / \mathrm{kg}$ ile maksimum güce ulaşmakta ve bu değerden sonra düşmektedir. \% 75 kompresör veriminde ise çevrim net gücü 4 kompresör basınç oranında $104,7 \mathrm{kj} / \mathrm{kg}$ ile maksimum güce ulaşarak bu değerden sonra düşmektedir.
Şekil 12a'da S- $\mathrm{CO}_{2}$ ve Şekil 12b'de Hava Brayton çevrimi için dört farklı türbin giriş basınç değerlerinde türbin giriş sıcaklıkları ile çevrim enerji verimi değişimi gösterilmiştir. S- $\mathrm{CO}_{2}$ (a) Brayton çevriminde çevrimin enerji verimini arttırmak için sabit türbin giriş basınç değerlerinde türbin giriş sıcaklık değerleri arttırıldığında çevrim enerji verimine etkisi olmadığı tespit edilmiştir. Bunu daha açık tanımlamak için Tablo 1'de $\mathrm{S}-\mathrm{CO}_{2}$ Brayton çevriminde sabit basınçta türbin sıcaklıklarının çevrim verimine olan etkisinden görebilmekteyiz. Örneğin $25 \mathrm{MPa}$ türbin giriş basıncı için $600^{\circ} \mathrm{C}$ sıcaklıkta çevrim enerji verimi $\% 13,92$ iken $800^{\circ} \mathrm{C}$ sıcaklıkta 
$\% 14,21$ ile maksimum verime ulaşmakta ve $1000^{\circ} \mathrm{C}$ sıcaklıkta \%14,20 verim ile maksimumdan düşerek devam etmektedir. Hava (b) Brayton çevriminde ise sabit türbin giriş basıncında türbin giriş sıcaklıkları arttırıldığında çevrim verimine olan etkisi az olmakla birlikte maksimum verime ulaşmak için sıcaklık $1000^{\circ} \mathrm{C}$ ' nin üzerindeki sıcaklıklarda olduğu görülmektedir. $\mathrm{S}-\mathrm{CO}_{2}$ (a) ve Hava (b) Brayton çevrimi için türbin giriş sıcaklıkları ile çevrim ekserji verimi ve türbin çıkış sıcaklıkları değişimi Şekil 13'de belirtilmektedir. Her iki çevrimde de görüldüğü gibi sabit türbin giriş basınçlarında türbin giriş sıcaklıkları arttığında ekserji verimi azalmaktadır.

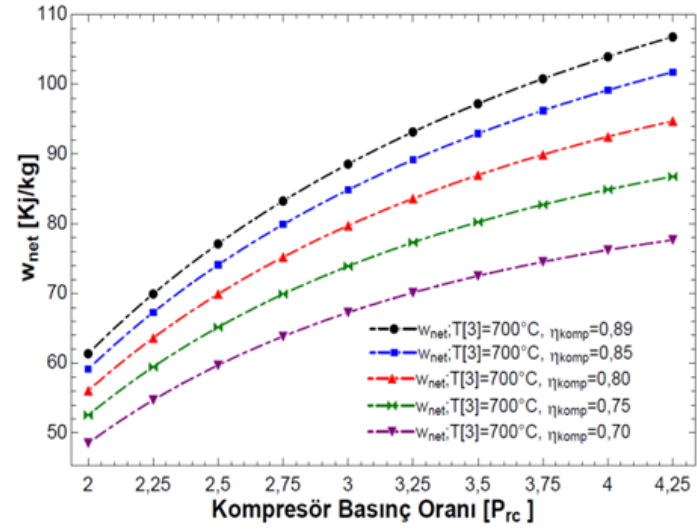

a

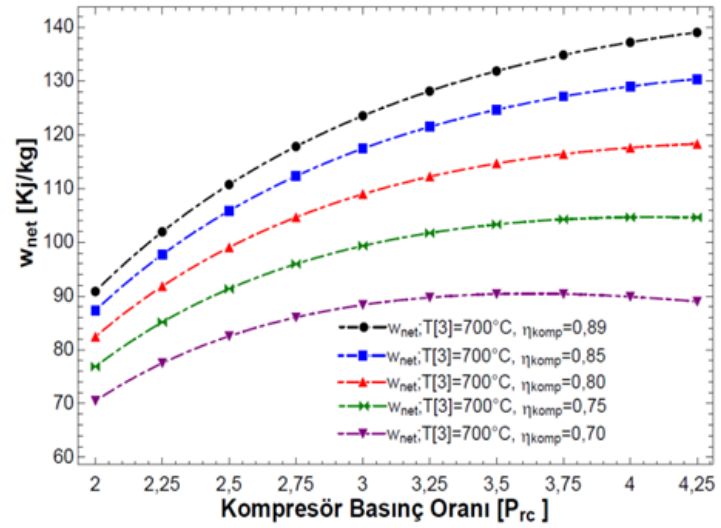

b

Şekil 11. a. S- $-\mathrm{CO}_{2}$, b. Hava Brayton çevrimi, farklı basınç oranlarında kompresör verimlerinin çevrim net güce etkisi

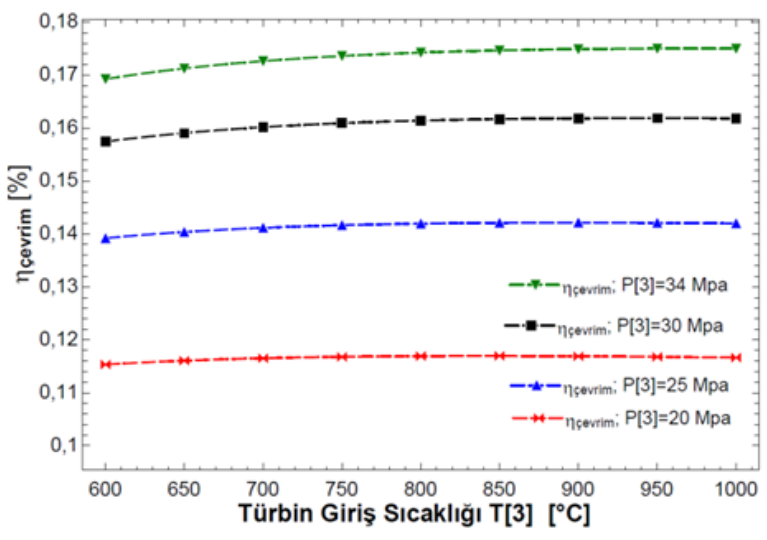

a

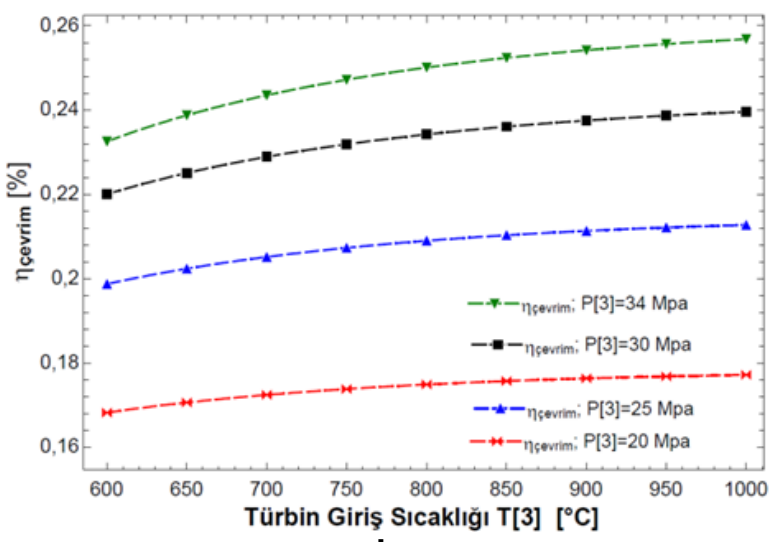

b

Şekil 12. a. S- $\mathrm{CO}_{2}$, b. Hava Brayton çevrimi türbin giriş sıcaklıkları ile çevrim enerji verimi değişimi

Tablo 1. S- $\mathrm{CO}_{2}$ Brayton çevriminde sabit basınçta türbin sıcaklıklarının çevrim enerji verimine olan etkisi

\begin{tabular}{|c|c|c|c|c|c|c|c|c|c|}
\hline $\mathrm{P}[3]$ & $600^{\circ} \mathrm{C}$ & $650^{\circ} \mathrm{C}$ & $700^{\circ} \mathrm{C}$ & $750^{\circ} \mathrm{C}$ & $800^{\circ} \mathrm{C}$ & $850^{\circ} \mathrm{C}$ & $900^{\circ} \mathrm{C}$ & $950^{\circ} \mathrm{C}$ & $1000^{\circ} \mathrm{C}$ \\
\hline $20 \mathrm{MPa}$ & 0,1153 & 0,1161 & 0,1165 & 0,1168 & 0,1169 & 0,1169 & 0,1169 & 0,1168 & 0,1166 \\
\hline $25 \mathrm{MPa}$ & 0,1392 & 0,1404 & 0,1412 & 0,1417 & 0,1419 & 0,1421 & 0,1421 & 0,1421 & 0,1420 \\
\hline $30 \mathrm{MPa}$ & 0,1574 & 0,1591 & 0,1602 & 0,1609 & 0,1614 & 0,1617 & 0,1618 & 0,1619 & 0,1618 \\
\hline $34 \mathrm{MPa}$ & 0,1693 & 0,1713 & 0,1727 & 0,1736 & 0,1743 & 0,1747 & 0,1749 & 0,1750 & 0,1750 \\
\hline
\end{tabular}




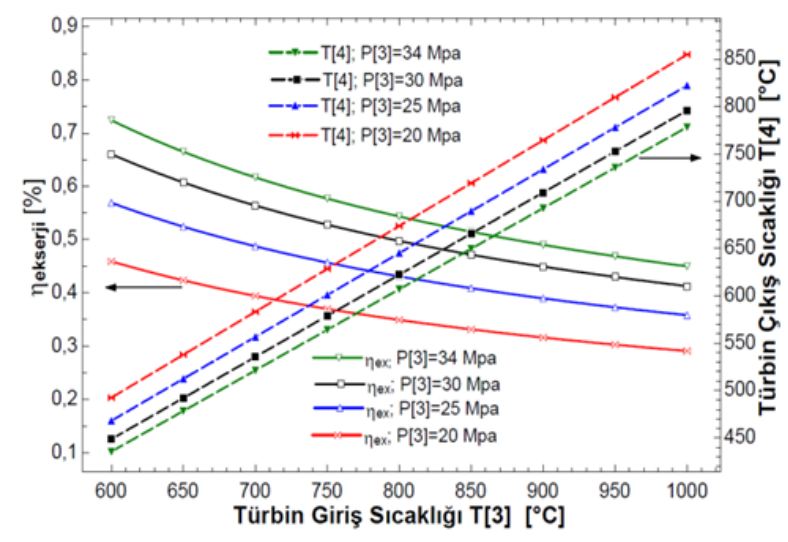

a

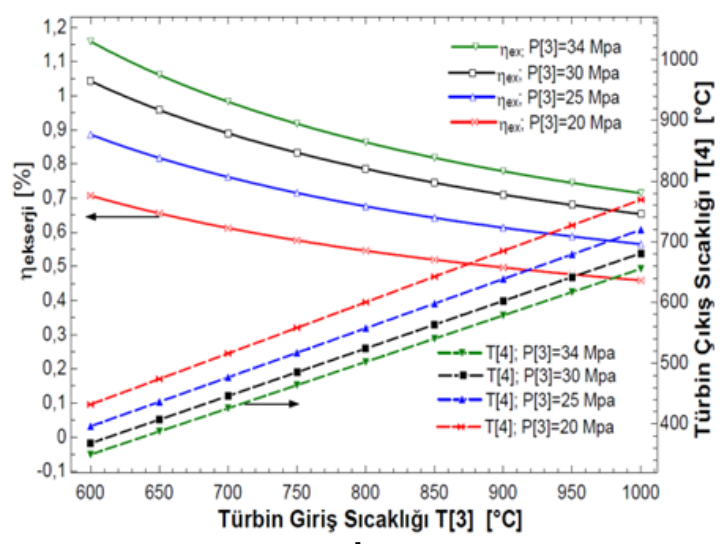

b

Şekil 13. a. S-CO $\mathrm{CO}_{2}$, b. Hava Brayton çevrimi türbin giriş sıcaklıkları ile çevrim ekserji verimi ve türbin çıkış sıcaklıkları değişimi

\section{SONUÇ}

Gaz türbini çevrimleri endüstriyel tesislerde kullanılmakla kalmayıp günümüzde savunma sanayi, uluslararası yük ve taşımacılık yapan gemilerde de sıkça tercih edilmektedir. Gaz türbinlerinin kullanım alanlarının artmasıyla üretilmek istenen enerjinin maliyetinin düşürülmesi için düşük dereceli atık ısı kaynaklarının etkin bir şekilde kullanılmasına yönelik çalışmalar her geçen gün daha fazla dikkat çekmektedir. Ancak maliyetlerin düşürülmesi için sadece atık ısı kaynaklarından faydalanmak tek başına yeterli değildir. Sistemde farklı akışkanlar kullanarak hem yüksek verim elde edilebilir hem de maliyetler en aza indirilebilir. Türbin giriş parametrelerinin yükselmesi, daha yüksek güç üretim verimi anlamına gelmektedir. Daha yüksek verim de sistemde, daha düşük emisyonların elde edilmesine yol açmaktadır. Bu sebeple türbin giriş sıcaklığının ve basıncının arttırılması, enerjinin etkin kullanılması ve çevrenin korunması açısından büyük önem arz etmektedir. Ancak türbin giriş sıcaklığı yükseldiğinde türbin kanatçıklarının yüzeyinde akma meydana gelmekte ve sıcaklık $621^{\circ} \mathrm{C}$ 'nin üzerine yükseltilememektedir (Dostal ve ark., 2004). Bunun önüne geçmek için türbin çelik malzemelerin yüzeyleri nikel alaşım ile kaplanmakta ve bu da maliyeti arttırmaktadır. Fakat türbin boyutları, bu üretimin geri dönüşebilir olmasının önünde engeldir. Bu durumda türbin boyutlarının küçülmesi, önemli bir kolaylık olacaktır. Bunun için aynı türbin giriş şartlarında, yoğun bir çevrim akışkanının kullanılmasına ihtiyaç vardır. Hem güvenlik hem de çevresel kriterler göz önüne alındığında, en makul çözümün çevrim akışkanı olarak $\mathrm{CO}_{2}$ in tercih edilmesi olacaktır. $\mathrm{CO}_{2}$ akışkanı sayesinde türbin ebatlarını çok küçük boyutlara düşürerek ilk yatırım maliyetlerini en aza indirmekle kalmayıp, sistemin performansının maksimum seviyelere yükseltmekle ve diğer akışkanlar ile rekabet edebilmektedir.

$\mathrm{Bu}$ çalışmada Süperkritik $\mathrm{CO}_{2}$ Brayton ve Hava Brayton çevriminin termodinamik analizi gerçekleştirilmiştir. Her iki çevrim içinde türbin giriş basıncı arttırıldığında çevrimin enerji-ekserji verimi ve çevrim net gücü arttığı görülmektedir. Sabit türbin giriş basıncında ise türbin giriş sıcaklıkları arttırıldığında çevrim enerji verimi ve net gücü artarken ekserji verimi azalmaktadır. Bununla birlikte çevrimler karşılaştırıldığında Hava Brayton çevriminde türbin giriş basıncı arttırıldığında çevrim net gücü maksimuma ulaşmakta daha sonra düşmektedir. $\mathrm{S}-\mathrm{CO}_{2}$ Brayton çevriminde ise bu durum çalışma parametrelerinin dışında olan oldukça yüksek türbin giriş basınçlarında meydana gelmektedir. Bu durumda $\mathrm{CO}_{2}$ 'in termofiziksel özellikleri ön plana çıkmakta ve Brayton çevrimlerinde tercih edilme sebebi olmaktadır. Karşılaştırmalara bakıldığında Hava Brayton çevrimi ve S- $\mathrm{CO}_{2}$ Brayton çevriminde çevrim akışkanları ve bu akışkanların termofiziksel özelliklerinden farklı olduğundan dolayı hava Brayton çevriminin çevrim enerji ekserji verimi değerleri daha yüksek olduğu görülmektedir. Ancak Hava Brayton çevriminde çalışma değerlerinde çevrim net gücü bir değerden sonra azaldığından dolayı uygun parametreler seçilerek çalıştırılması gerekmektedir. S- $\mathrm{CO}_{2}$ Brayton çevriminde ise çalışma değerlerinde bu tür problemler bulunmamaktadır.

Kompresör verim değerleri incelendiğinde, aynı türbin giriş sıcaklığı için, çevrim enerji verimini maksimum yapan optimum kompresör basınç oranı, net gücü maksimum yapan değerinden daima büyük çıkmaktadır.

Çevrimde maksimum net güce ve çevrim enerji verimine ulaşmak için, düşük kompresör verimli kompresörlerde, düşük kompresör basınç oranları, yüksek 
kompresör verimli kompresörlerde ise yüksek kompresör basınç oranları tercih edilerek sistemin çalıştırılması gerekmektedir.

S- $\mathrm{CO}_{2}$ Brayton çevriminde elde edilen veriler göstermektedir ki diğer gaz akışkanlı güç çevrimleri için verilen verimlilik değerleri ile rekabet edebilir ölçektedir. Belirli çevrim çalışma koşullarında optimum gaz ısıtıcı basıncı, artan ısı kaynağı sıcaklığı ile artmaktadır. Optimum gaz ısıtıcı basıncının yanı sıra optimum bir gaz soğutucu basıncının da elverişli çalışması gerekmektedir. Ayrıca, türbin verimliliği, çevrimin enerji verimliliği üzerinde kompresör verimliliğinden daha önemli bir etkiye sahiptir. $\mathrm{S}-\mathrm{CO}_{2}$ Brayton çevriminde daha yüksek verim sağlamak için ara soğutmalı, yeniden ısıtmalı ve rejeneratör gibi ekipmanlar tercih edilerek sistem daha elverişli ve ekonomik çalışılacaktır.

\section{KAYNAKLAR}

Ahn, Y., Bae, S.J., Kim, M., Cho, S.K., Baik, S., Lee, J.I., Cha, J.E. (2015). Review of supercritical $\mathrm{CO}_{2}$ power cycle technology and current status of research and development. Nuclear Engineering and Technology, 47: 647661.

Angelino, G. (1968). Carbon dioxide condensation cycles for power production. Journal of Engineering for Gas Turbines and Power, 90: 287-295.

Coms, O.V. (1997). An Investigation of the supercritical $\mathrm{CO}_{2}$ cycle (feher cycle) for shipboard application. Massachusetts Institute of Technology, Massachusetts, USA.

Çengel, Y.A., Boles, M.A. (2008). Termodinamik: Mühendislik Yaklaşımıyla. Güven Kitabevi, İzmir.

Çetin, B. (2017). Basit Brayton çevriminde elektrik üretimi maliyetinin parametrik analizi. FIrat Üniversitesi Mühendislik Bilimi Dergisi, 29(2):1-8.

Dostal, V., Driscoll, M.J., Hejzlar, P.A. (2004). Supercritical carbondioxide cycle for next generation nuclear reactors. Massachusetts Institute of Technology Center for Advanced Nuclear Power Technology Program, Massachusetts, USA.

Holcomb, G.R., Doğan, Ö.N., Carney, C., Rozman, K., Hawk, J.A., Anderson, M.H. (2016). Materials perfor- mance in supercritical $\mathrm{CO}_{2}$ in comparison with atmospheric pressure $\mathrm{CO}_{2}$ and supercritical steam. The $5^{\text {th }} \mathrm{Su}$ percritical $\mathrm{CO}_{2}$ Power Cycle Symposium. San Antonio, Texas, USA, 29-31.

Horlock, J.H. (1997). Aero-engine derivative gas turbines for power generation: thermodynamic and economic perspectives. Journal of Engineering for Gas Turbines and Power, 119(1): 119-123.

Kato, Y., Nitawaki, T., Muto, Y. (2004). Medium temperature carbon dioxide gas turbine reactor. Nuclear Engineering and Design, 230(1-3): 195-207.

Kim, H.M., Pettersen, J., Bullard, C.W. (2004). Fundamental process and system design issues in $\mathrm{CO}_{2}$ vapor compression systems. Progress in Energy and Combustion Science, 30: 119-174.

Klein S.A. (2020). EES, Engineering Equation Solver, FChart Software. www.fchart.com/ees/ees.shtml

Korpela S. (2011). Principles of turbo machinery. A John Wiley \& Sons, Incules, Hoboken, New Jersey, USA.

Muto, Y., Watanabe, N., Aritomi, M., Ishizuka, T. (2016). Dependence of thermal efficiency on receiver temperature of solar thermal Power systems combined with supercritical $\mathrm{CO}_{2}$ gas turbine cycle and Brayton $\mathrm{CO}_{2}$ gas turbine cycle. The Fifth International Symposium, Supercritical $\mathrm{CO}_{2}$ Power Cycles March 29-31, 2016, San Antonio, Texas, USA.

Özgür, A.E. (2014). $C_{2}$ Soğutkanlı transkritik soğutma çevrimlerinde optimum gaz soğutucu basıncı ve literatürdeki optimum basınç denklemlerinin karşılaştırılması. Tesisat Mühendisliği Dergisi, 141:43-47.

Özgür, A.E., Ceylan, V. (2019). $\mathrm{CO}_{2}$ akışkanlı transkritik bir güç çevriminin termodinamik analizi. $22^{\text {nd }}$ Thermal Science and Technology Congress, Eylül 11-14, Kocaeli.

Padilla, R.V., Soo Too, Y.C., Benito, R., Stein, W. (2015). Exergetic analysis of supercritical $\mathrm{CO}_{2}$ Brayton cycles integrated with solar central receivers. Appl. Energy, 148(C): 348-365.

Tozlu, A., Özahi, E., Abuşoğlu, A. (2017). Organik Rankine çevrimi entegre edilmiş $\mathrm{S}-\mathrm{CO}_{2}$ kullanılan bir gaz türbin çevriminin termodinamik ve termoekonomik analizi. Gazi Üniversitesi Mühendislik ve Mimarlık Fakültesi Dergisi, 33(3): 917-928.

Wright, S., Radel, R., Vernon, M., Rochau, G., Pickard, P. (2010). Operation and analysis of a supercritical $\mathrm{CO}_{2}$ Brayton cycle. Advanced Nuclear Concepts Department Sandia National Laboratories. Albuquerque, New Mexico 87185 and Livermore, California 94550. 